\title{
PENGUASAAN BUDAYA INDONESIA DALAM TULISAN IMAJINATIF (STUDI KASUS SISWA DI SACRED HEART GIRLS COLLEGE, AUSTRALIA)

\author{
Mastering Indonesian Culture in Imaginative Writing \\ (Student Case Study in the Sacred Heart Girls College, Australia)
}

Derri Ris Riana

Balai Bahasa Kalimantan Selatan

Jalan Jenderal Ahmad Yani Km 32, Loktabat, Banjarbaru, Kalimantan Selatan

Pos-el: derririsriana@yahoo.co.id

Diterima: 30 November 2018; Direvisi: 20 Desember 2018; Disetujui: 20 Desember 2018

DOI: http://dx.doi.org/10.26499/sawer.v24i2.508

\begin{abstract}
Learning Indonesian culture and Indonesia language for forigners (BIPA) is quite closely related. However, there have been many researches regarding cultural mastery of BIPA students in imaginative writing. By using literary anthropological method supported by Kroeber and Kluckhohn, this research aims to reveal Indonesian cultural images in imaginative writing of BIPA students in Sacred Heart Girls College and the connection between Indonesian cultural mastery and the complete of the story. The result shows the category of Indonesian culture in sixth imaginative writings, are normative behavior ("Berubah Menjadi Tikus" and "Sesuatu di Balik Bantal"), custom ("Burung Toti" dan "Lima Hari"), history on social heritage and tradition ("Blangkon"), psychology, arrangement ("Sesuatu di Balik Bantal"), and psychology, learning ("Terlewat Perjalanan dari Bantal"). Indonesian cultural mastery and the complete elements of story are interrelated. If culture footing is good, the story will be complete. The incompleteness of a story is seen from the unwell conveyed description, character, and culture shows their lack of understanding of Indonesian culture.
\end{abstract}

Keywords: Indonesian language for foreigners; imaginative writing; culture; story elements

\begin{abstract}
Abstrak
Pemahaman budaya Indonesia dalam pembelajaran bahasa Indonesia bagi penutur asing (BIPA) cukup erat kaitannya. Akan tetapi, belum banyak penelitian tentang penguasaan budaya pemelajar BIPA dalam tulisan imajinatif. Dengan menggunakan metode antropologi sastra yang didukung oleh pendekatan budaya dari Kroeber dan Kluckhohn, penelitian ini bertujuan untuk mengungkap gambaran budaya Indonesia dalam tulisan imajinatif pemelajar BIPA di Sacred Heart Girls College dan keterkaitan antara penguasaan budaya Indonesia dan kelengkapan unsur-unsur cerita. Hasil penelitian menggambarkan kategori budaya Indonesia dalam keenam cerita, yaitu perilaku normatif ("Berubah Menjadi Tikus" dan "Sesuatu di Balik Bantal"), kebiasaan ("Burung Toti" dan "Lima Hari"), sejarah pada warisan sosial dan tradisi (cerita "Blangkon"), psikologi, pengaturan (cerita "Sesuatu di Balik Bantal"), psikologi, dan pembelajaran (cerita "Terlewat Perjalanan dari Bantal"). Penguasaan budaya Indonesia dan kelengkapan unsur-unsur cerita saling terkait. Jika pijakan budaya tidak kuat, cerita yang disampaikan tidak utuh. Ketidaklengkapan cerita itu terlihat pada penyampaian latar tempat dan tokoh, serta budaya yang tidak detail sehingga menunjukkan kekurangpekaan budaya Indonesia.
\end{abstract}

Kata kunci: BIPA; tulisan imajinatif; budaya; unsur cerita 


\section{PENDAHULUAN}

Pemahaman budaya Indonesia dalam pembelajaran bahasa Indonesia, khususnya bagi pemelajar bahasa Indonesia bagi penutur asing (BIPA) cukup erat kaitannya. Pembelajaran bahasa tidak hanya mempelajari struktur bahasa, tetapi juga budaya yang dituturkan pengguna bahasa tersebut. Dengan memahami budaya Indonesia, pemelajar BIPA akan mampu menggunakan bahasa Indonesia yang baik dan benar seperti penutur jati bahasa Indonesia. Penelitian tentang keterkaitan antara pentingnya pembelajaran budaya dan pembelajaran BIPA juga banyak dilakukan, seperti penelitian Suyitno (2017) dalam "Pemahaman Budaya dalam Pembelajaran Bahasa Indonesia bagi Penutur Asing (BIPA)" menyampaikan bahwa materi budaya Indonesia digunakan sebagai bahan ajar yang dikemas dalam materi berupa teks atau dialog. Penelitian tersebut lebih menitikberatkan pada penerapan materi budaya dalam pembelajaran BIPA.

Pemahaman terhadap Indonesia secara keseluruhan, baik bahasa maupun budaya akan menumbuhkan kecintaan terhadap Indonesia sehingga citra Indonesia di dunia internasional semakin terangkat. Selain untuk menginternasionalkan bahasa Indonesia, pembelajaran BIPA juga digunakan sebagai soft diplomacy untuk mendekatkan hubungan antarkedua negara. Hubungan antarnegara ini seringkali mengalami pasang surut yang disebabkan oleh beberapa hal, khususnya dalam bidang politik. Untuk lebih memupuk dan mempererat hubungan antarnegara tersebut, salah satunya adalah penetrasi budaya melalui pembelajaran bahasa. Australia adalah negara yang memiliki hubungan cukup dekat dengan Indonesia. Akan tetapi, hubungan politis seringkali menyebabkan ketegangan hubungan antarkedua negara tersebut. Oleh karena itu, pengajaran BIPA di Australia diharapkan mampu tetap mempererat kecintaan masyarakat Australia terhadap Indonesia.

Pengajaran BIPA di Australia cukup maju karena sekitar 500 sekolah yang mengajarkan bahasa Indonesia. Perkembangan pengajaran BIPA yang cukup signifikan itu disebabkan oleh beberapa faktor, yaitu kedekatan hubungan Indonesia dan Australia, kebermanfaatan bahasa Indonesia di berbagai bidang, dan tingkat kesulitan belajar yang relatif rendah. Akan tetapi, pada saat ini perkembangan tersebut agak menurun karena berbagai hal, yaitu hubungan politis dan penetrasi bahasa Cina secara besarbesaran. Sacred Heart Girls College adalah salah satu sekolah menengah atas di Victoria, Australia yang mengajarkan bahasa Indonesia. Di sekolah ini ada tiga bahasa asing yang diajarkan, yaitu bahasa Indonesia, Prancis, dan Italia. Bahasa Indonesia wajib diajarkan bagi siswa di kelas 7, 8, 9 sedangkan pada kelas 10 bisa tidak diwajibkan. Sementara itu, di kelas 11 dan 12 pelajaran bahasa Indonesia sudah menjadi pilihan.

Di Sacred Heart Girls College siswa tingkat akhir sekolah menengah atas adalah siswa VCE kelas 12. Kemampuan bahasa Indonesia mereka rata-rata bagus karena dapat diuji secara lisan ataupun tulis dalam ujian VCE (Victorian Certificate of Education). Ujian akhir VCE tersebut terdiri atas oral examination/ ujian lisan dan written examination/ ujian tulis. Ujian lisan terdapat dua bagian, yaitu percakapan umum selama sekitar tujuh menit dan diskusi topik tertentu selama sekitar delapan menit. Sementara itu, ujian tulis terdapat tiga bagian yang harus dikerjakan siswa. Bagian pertama adalah mendengarkan dan menanggapi, bagian kedua adalah membaca dan menanggapi, dan bagian ketiga adalah menulis dalam bahasa Indonesia. Jenis tulisan siswa yang dihasilkan berupa tulisan informatif, persuasif, imajinatif, dan evaluatif. Dari tulisan-tulisan tersebut secara umum mereka mampu menyampaikan ide/gagasan ke dalam bahasa Indonesia sesuai dengan jenis tulisan yang dimaksud. Akan tetapi, masih terlihat kedangkalan budaya Indonesia dalam tulisan imajinatif siswa.

Walaupun sudah ada yang mengaitkan budaya dan pembelajaran bahasa Indonesia, belum banyak penelitian yang mengkaji 
penguasaan budaya pemelajar BIPA yang terlihat dalam tulisan, khususnya tulisan imajinatif. Berdasarkan uraian di atas, pokok permasalahan dalam penelitian ini adalah bagaimana gambaran budaya Indonesia dalam tulisan imajinatif pemelajar BIPA di Sacred Heart Girls College dan bagaimana keterkaitan antara penguasaan budaya Indonesia dan kelengkapan unsur-unsur pendukung cerita. Adapun, tujuan penelitian ini adalah menggambarkan budaya Indonesia dalam tulisan imajinatif pemelajar BIPA di Sacred Heart Girls College dan memaparkan keterkaitan antara penguasaan budaya Indonesia dan kelengkapan unsur cerita.

\section{KERANGKA TEORI}

Keterampilan menulis dalam rancangan pembelajaran VCE (Victorian Certificate of Education) terdapat beberapa jenis tulisan yang harus dikuasai oleh pemelajar bahasa Indonesia, yaitu tulisan personal, imajinatif, persuasif, informatif, dan evaluatif. Borroway (2015: 16) menyatakan bahwa tulisan imajinatif merupakan tulisan yang membangkitkan kesan indera dalam pikiran sehingga pembaca dapat melihat, mendengar, mengalami, dan merasakan sesuatu melalui imajinasi yang telah diciptakan. Kemampuan penulis dalam menuangkan kata-kata itu akan membuat tulisan imajinatif seolah-olah hidup sehingga dapat dirasakan dan ditangkap oleh pembaca yang akhirnya menimbulkan kepuasan tersendiri (Semi, 1988: 27).

Menurut Semi (1988: 15), pengucapan atau tulisan yang tergolong ke dalam jenis kreatif-imajinatif disebut sebagai kesusastraan atau karya sastra. Cerita pendek merupakan sebuah karya sastra yang berbentuk ringkas yang berangkat dari fakta pengalaman batin seorang pengarang. Kemudian, dari fakta itu dikreasikan kembali dengan imajinasi sehingga menjadi suatu yang hidup Thahar (1999: 17). Menurut McNamee, dkk (1971:15) cerita pendek merupakan pengungkapan beberapa aspek-aspek kehidupan di mana tokoh memiliki waktu terbatas untuk menyelesaikan tujuannya.
Setiap penulis memiliki kekhasan tersendiri dalam mengkreasikan daya imajinasinya sehingga cerpen yang dihasilkannya pun menjadi berbeda antarpenulis. Cerpen yang menonjolkan daya imajinasi yang tinggi dengan menampilkan cerita yang tingkat kebenarannya diragukan bisa dikategorikan ke dalam cerita fantasi (Nurgiyantoro, 2013: 297). Cerpen yang berdasarkan pada fantasi tersebut terlihat pada beberapa cerpen yang akan diteliti, yaitu tentang tokoh yang berubah menjadi tikus, tokoh yang menemukan blangkon kemudian berpindah ke masa lalu, seekor burung yang bisa berbicara dan memiliki jalan pikiran, dll.

Keutuhan sebuah cerita dibentuk oleh unsur-unsur pendukung cerita yang saling berkaitan satu dengan yang lain secara erat dan saling menguntungkan (Nurgiyantoro, 1998: 22). Unsur-unsur itu tidak hanya membangun cerita dari dalam, tetapi juga dari luar. Unsur yang membangun cerita dari luar disebut sebagai unsur ekstrinsik, misalnya latar belakang penulis. Latar belakang sosial, budaya, pandangan hidup si penulis secara tidak langsung akan mempengaruhi isi cerita. Kepekaan terhadap pengenalan dan penggalian budaya yang lebih mendalam akan lebih memperkaya dan mengutuhkan sebuah cerita. Menurut Levine (2009: 4) budaya merupakan seperangkat aturan yang terorganisasi yang berkaitan dengan cara individu dalam populasi bisa berkomunikasi antara satu dengan yang lain, berpikir tentang mereka sendiri dan lingkungan, serta bersikap antara satu sama lain dan antarobjek di dalam lingkungannya.

Menurut Weiss (1973: 1397) Elemen budaya merupakan sistem pokok yang terdiri atas seperangkat komponen pokok (manusia dan bukan manusia), seperangkat perubahan (neural dan fisik), dan seperangkat hubungan organisasi (sosial dan teknis). Sementara itu, Kroeber dan Kluckhohn dalam Baldwin (2006: 7-8) membagi pengertian budaya ke dalam enam kategori, yaitu (1) deskriptif enumeratif (daftar isi budaya), sejarah (penekanan pada warisan sosial, tradisi), (3) normatif (fokus pada perilaku 
yang dicita-citakan), (4)psikologi(pembelajaran, kebiasaan, pengaturan, sarana pemecah masalah), (5) struktur (fokus pada pola organisasi budaya), dan (6) genetik (simbol, ide, artefak). Bahasa adalah satu contoh unsur budaya yang di dalamnya tercermin pemikiran seseorang yang dilontarkan dalam setiap pemilihan kata-kata. Adanya perbedaan yang mendasar pada sebuah bahasa antara penggunaan bahasa yang baik dan benar tergantung pada aturan pemilihan kata, struktur, sintaksis. Karakter bahasa itu sendiri bisa sangat berbeda dari norma lain yang ada dalam budaya yang sama dengan pematuhan (Parsons, 1972: 256).

Jika ingin membuat cerita tentang tokoh dalam kebudayaan negara tertentu, tentu budaya tokoh yang bersangkutan harus digali lebih mendalam dan sesuai dengan budaya masyarakat yang dimaksud. Kebanyakan tulisan imajinatif pemelajar BIPA masih belum menggali lebih dalam mengenai budaya Indonesia sehingga tulisan yang dihasilkan menjadi dangkal atau belum tereksplorasi lebih lanjut. Apabila pengajaran BIPA ditata secara integratif, pengetahuan pemelajar BIPA terhadap bahasa dan budaya Indonesia akan mumpuni. Oleh karena itu, menurut Jumadi (2017: 134) sebaiknya pengelolaan materi dan pengajaran BIPA memperhatikan tiga hal, yaitu pengajaran menitikberatkan pada (1) materi yang trainable, faktual, serta situasional dan kontekstual, (2) penggunaan bahasa Indonesia praktis yang meliputi kosakata, lafal dan intonasi, pola kalimat, wacana percakapan, dan pengolahan ide, dan (3) materi pengajaran ditata berdasarkan unit-unit satuan yang komunikatif secara integratif.

\section{METODE}

Penelitian ini akan mengungkap penguasaan budaya Indonesia dalam tulisantulisan imajinatif karya siswa kelas $12 \mathrm{VCE}$ di Sacred Heart Girls College, yaitu "Berubah Menjadi Tikus", "Blangkon", "Burung Toti", "Sesuatu di Balik Bantal", "Terlewat dari Perjalanan", dan "Lima Hari”. Sumber-sumber primer itu didukung dengan sumber sekunder berupa data informasi yang telah dibuat penulis dalam laporan "Pengajaran BIPA di Sacred Heart Girls College, Victoria, Australia". Karena tujuan penelitian adalah mengungkapkan budaya, khususnya budaya Indonesia dalam tulisan imajinatif pemelajar BIPA, metode yang digunakan dalam penelitian ini adalah antropologi sastra.

Dalam penelitian ini, penulis menggali budaya yang ada di dalam tulisan imajinatif siswa berdasarkan pada prinsip-prinsip budaya dengan pendekatan antropologi sastra. Poyatos (1988: xii) memaparkan bahwa pendekatan antropologi sastra berdasarkan pada penggunaan literatur naratif yang berorientasi secara antropologi pada budaya yang berbeda karena dari situ terdapat sumber dokumentasi paling banyak untuk analisis sinkronis dan diakronis dari tindakan dan ide manusia. Pada pendekatan antropologi sastra salah satu pokok bahasan yang dapat dikaji adalah aspek-aspek naratif karya sastra dari kebudayaan yang berbeda (Ratna, 2006: 64-65).

Pada penelitian ini aspek-aspek naratif pada tulisan-tulisan imajinatif siswa dari penulis yang memiliki pengetahuan latar belakang budaya berbeda akan dikaji lebih lanjut. Keenam tulisan imajinatif akan dilakukan analisis budaya berdasarkan prinsip-prinsip budaya Kroeber dan Kluchkohn untuk memperoleh gambaran budaya yang ada di dalam keenam tulisan tersebut. Kemudian, dari analisis budaya tersebut ditindaklanjuti dengan melihat keterkaitan antara penguasaan budaya Indonesia dan kelengkapan unsur-unsur-unsur cerita.

\section{PEMBAHASAN}

\section{Gambaran Budaya Indonesia dalam Tulisan Imajinatif Pemelajar BIPA di Sacred Heart Girls College}

Tulisan-tulisan imajinatif yang dijadikan objek penelitian adalah hasil karya siswa kelas 12. Dalam ujian akhir siswa kelas 12 ada dua ujian, yaitu ujian lisan (oral examination) dan ujian tulis (written examination). Salah satu 
ujian tulis pada ujian akhir itu adalah membuat sebuah tulisan. Jenis tulisan yang bisa dipilih oleh siswa adalah tulisan imajinatif. Di lembar soal ujian akhir itu siswa sudah diberi panduan cerita berupa penggalan cerita. Jadi, siswa hanya meneruskan penggalan cerita itu. Penggalan cerita yang dibuat biasanya berupa cerita fantasi yang bisa merangsang siswa untuk berimajinasi meneruskan cerita itu. Keenam tulisan imajinatif, hasil karya siswa berupa manusia berubah menjadi tikus, seseorang menemukan blangkon kemudian berpindah waktu ke zaman dulu, burung yang bisa berbicara dan berpikir, seseorang menemukan sesuatu di balik bantal, seseorang yang terlewat perjalanan dari Bandung, dan seseorang yang terdampar di sebuah pulau selama lima hari.

Dalam tulisan imajinatif tersebut tergambar kemampuan berbahasa Indonesia pemelajar BIPA. Kemampuan tersebut akan terlihat dari penggunaan tata bahasa, penguasaan isi (salah satunya adalah budaya Indonesia), dan penguasaan unsur-unsur cerita. Salah satu keberhasilan pembelajaran bahasa Indonesia adalah ketika penguasaan bahasa sejalan dengan penguasaan budaya. Berbahasa Indonesia yang baik dan benar tidak hanya tergantung pada tata bahasa sesuai kaidah, tetapi juga sesuai situasi dan kondisi. Situasi dan kondisi itu akan mudah dipahami jika pengetahuan budaya bagus. Dengan menguasai bahasa Indonesia dan budayanya, kemampuan pemelajar BIPA akan terlihat seperti penutur jati bahasa Indonesia.

Representasi budaya Indonesia terlihat dari keenam tulisan imajinatif yang dipilih. Tulisan berjudul "Menjadi Seekor Tikus" memperlihatkan budaya Indonesia yang tercermin pada tokoh "aku" yang berubah menjadi tikus. Sesuai pendekatan budaya yang disampaikan oleh Kroeber dan Kluckhohn, salah satu elemen budaya adalah normatif, yaitu pola perilaku yang berpedang pada aturan yang berlaku. Pada cerita ini secara tersirat ada perilaku normatif yang terlihat pada tokoh "aku" yang berubah menjadi seekor tikus bahwa seorang anak sebaiknya memberitahu orang tua jika ingin pergi dari rumah. Akan tetapi, tokoh "aku" tersebut tidak mematuhi aturan di dalam keluarga, yaitu kabur dari rumah. Adanya hukuman setelah kabur dari rumah, yaitu berubahnya tokoh menjadi seekor tikus yang akhirnya hidup menderita memperlihatkan ketidaktaatan terhadap perilaku normatif di masyarakat. Pelanggaran prinsip normatif yang berakibat pada hukuman pada tokoh "aku" menunjukkan prinsip normatif budaya terjaga. Kutipan yang menyatakan penyesalan tokoh "aku" karena telah kabur dari rumah pada tulisan berjudul "Menjadi Seekor Tikus" terlihat pada kutipan berikut.

"Maaf, Bu,"kataku. Aku menghadap wajah ibuku. Wajah ini wajah yang aku rindu selama empat tahun. "Saya nyasar. Saya janji. Saya tidak akan lari lagi dari rumah," kataku sambil menangis.

"Tidak apa-apa, Nak", kata ibuku.

Beeep! Suara mobil membangunkanku. Huh? Terbangun dari mimpiku. Aku lihat di sekitarku. Oh.. aku masih di sini. Aku masih seekor tikus. Seperti biasa aku cepat-cepat menghapus air mataku. Ini kesalahanku sendiri. Oleh sebab itu, aku harus bertanggung jawab.

Prinsip budaya yang juga tampak pada tulisan "Berubah Menjadi Tikus" adalah pola perilaku masyarakat yang mengarah pada kebiasaan karena dilakukan secara rutin. Kebiasaan itu tergambar pada kegiatan manusia di dalam masyarakat, yaitu di pasar. Di dalam cerita ini digambarkan bahwa di pasar banyak terdapat penjual yang sedang menjajakan barang dagangannya, misalnya penjual makanan dan buah-buahan. Di Indonesia penjual di pasar menawarkan dagangannya dengan berbagai cara untuk menarik pembeli, yaitu berteriak menjajakan makanan.

Penggambaran budaya yang terdapat pada tulisan imajinatif berjudul "Blangkon" berkenaan dengan sejarah (penekanan pada warisan sosial dan tradisi) sesuai dengan prinsip budaya yang disampaikan oleh Kroeber dan 
Kluckhohn. Sejarah yang ditampilkan dalam cerita berkaitan dengan sejarah Jawa, khususnya tentang blangkon, penutup kepala tradisional Jawa yang biasa dipakai oleh laki-laki. Sesuai dengan budaya Jawa, blangkon memiliki makna filosofis yang dalam dan memang diperuntukkan hanya dipakai oleh laki-laki. Dalam cerita ini secara implisit blangkon juga hanya dipakai oleh laki-laki. Hal itu tampak ketika menemukan dan memakai sebuah blangkon di lantai museum, tokoh "aku" yang notabene seorang perempuan seketika berubah menjadi laki-laki Jawa. Perubahan tokoh perempuan menjadi tokoh lakilaki tersebut menonjolkan tradisi penggunaan blangkon dalam masyarakat Jawa. Blangkon yang lekat dengan budaya Jawa itu dapat dilihat pada kutipan berikut ini.

Tiba-tiba saya menemui sebuah topi di lantai. Saya ingat saya pernah belajar tentang topi ini. Topi ini bernama blangkon yang pernah dipakai oleh seorang Pangeran Jawa pada tahun 1400-an. Saya mengangkat topinya, menjalan ke depan cermin terdekat dan mencobakannya.

Tiba-tiba orang yang berada di cermin itu bukan saya, tetapi seorang laki-laki di sebuah kamar. Selain itu, terlihatnya bukan zaman ini, tetapi zaman dahulu. Saya teriak sekencang mungkin. Tidak, ini tidak mungkin. Saya pasti sedang bermimpi. Hal-hal ini hanya terjadi di film-film.

Pada cerita "Burung Toti" salah satu kategori budaya yang disampaikan oleh Kroeber dan Kluckhohn adalah psikologi yang termasuk di dalamnya kebiasaan. Kebiasaan yang menonjol dalam cerita itu adalah kebiasaan makan daging burung bagi sebagian masyarakat Indonesia. Daging burung yang biasa dikonsumsi biasanya daging burung dara. Akan tetapi, dalam cerita ini tidak secara gamblang dideskripsikan jenis daging burung yang akan dikonsumsi. Dari perilaku tokohnya tercermin bahwa ia suka makan daging burung. Kenyataan itu terlihat ketika tokoh, yaitu 'Si Pria' mencari burung ke toko burung yang disuruh oleh 'Si Bos'. Karena burung yang dicari digunakan untuk dikonsumsi, 'Si Pria' itu pun mencarikan burung yang masih muda. Burung yang masih muda memiliki tekstur daging yang masih lembut. Berikut ini kutipan yang menyatakan secara tersirat kebiasaan makan daging burung yang masih muda.

"Sip boss" dia berkata saat dia berbicara di teleponnya. "Saya memilih yang termuda sebab saya tau bos suka daging yang lembut."

Matanya membelakangiku. "Dan percayalah bahwa daging ini sangat segar".

Kategori budaya pada cerita 'Sesuatu di Balik Bantal” sesuai dengan deskripsi Kroeber dan Kluckhohn terdapat pada kategori psikologi, khususnya pengaturan. Pada kategori ini ada tokoh yang berperan sebagai pengatur untuk membuat sesuatu menjadi lebih baik. Tokoh itu digambarkan sebagai seorang ibu yang mengatur anaknya untuk berperilaku baik. Sang ibu mengajari anaknya untuk membersihkan rumah. Walaupun sebenarnya pekerjaan itu bisa dikerjakan, sang ibu tetap memberikan kesempatan kepada anak-anaknya supaya membentuk kehidupan yang lebih mandiri. Pengaturan ini masuk ke ranah budaya karena menggambarkan pola pengaturan hidup, khususnya di lingkungan keluarga. Hal itu bisa kita buktikan di dalam kutipan pada cerita tersebut.

"Toti! Cepat! Bersihkanlah ruang keluarga!"kata ibuku sambil keluar rumah. "Waktu Ibu kembali, ibu mau seluruh ruang keluarga sudah dibersihkan!" Ibu sedang bersiap-siap untuk pergi ke toko untuk membeli makanan untuk minggu ini.

"Ya, Bu!" jawabku sambil pergi ke pintu depan untuk menguncinya.

Dalam cerita "Sesuatu di Balik Bantal" juga ada perilaku normatif yang ditunjukkan oleh tokoh Ibu. Perilaku ideal sosok ibu terlihat pada cerita tersebut. Tokoh ibu digambarkan secara tersirat melalui dialog-dialog dalam cerita 
tentang tugas seorang ibu. Beberapa di antaranya adalah membersihkan rumah, mengurus anakanak, menyiapkan makanan, dll. Gambaran seorang ibu adalah seseorang yang idealnya bertugas di rumah.

Kategori budaya pada cerita 'Terlewat Perjalanan dari Bandung" adalah psikologi, khususnya pembelajaran. Pembelajaran yang dimaksud dalam cerita ini adalah mengambil makna dari setiap perbuatan. Pembelajaran itu dialami oleh tokoh ketika secara tidak sengaja melewatkan perjalanannya yang seharusnya ke Bandung malah ke Yogyakarta. Awalnya ia menggerutu dengan apa yang dialaminya, tetapi lama-kelamaan ia pun menerima dengan iklas. Oleh karena itu, dibalik keteledorannya itu ia memperoleh hikmah, yaitu berupa pelajaran positif dari risiko yang telah diambilnya. Proses itu terlihat pada kutipan berikut ini.

Itu terjadi lima tahun yang lalu. Pada hari itu hidupku berubah secara drastis. Saya mulai melakukan banyak hal yang dulu saya tidak akan berpikir. Sekarang hidupku penuh dengan cerita-cerita yang sangat menarik karena risiko-risiko yang saya ambil.

Walaupun kadang-kadang banyak hal tidak terjadi seperti keinginan Anda, selalu melihat aspek-aspek yang positif dari pengalaman itu.

Selain itu, kategori budaya lain juga tampak pada kebiasaan masyarakat Indonesia yang ramah dan perhatian. Pada cerita "Terlewat Perjalanan dari Bandung" kebiasaan itu digambarkan pada perilaku antartokoh. Ketika mengetahui bahwa telah salah rute dalam menempuh perjalanan kereta dari pengumuman yang telah diperdengarkan, tokoh 'aku' memastikan hal tersebut kepada penumpang yang lain. Ia bertanya dengan sopan kepada penumpang tentang keberadaan dirinya. Ternyata penumpang itu membalas pertanyaannya dengan ramah dan hangat. Hal itu ditunjukkan dengan sapaan yang hangat dan gerak tubuh yang bersahabat walaupun belum mengenal secara personal sebelumnya. Keramahan masyarakat tampak secara tersirat pada dialog tokoh berikut.

"Permisi, Bu, tetapi kita di mana?" tanya aku kepada wanita tua yang duduk di sebelahku.

"Di Tasikmalaya, Neng" kata dia dengan senyuman yang sangat hangat.

Waduh! Tasikmalaya itu sudah jauh dari Bandung

"Mengapa Neng?" tanya ibu itu.

"Oh tidak Bu" kataku dengan senyum.

Pada cerita berjudul 'Lima Hari' kategori budaya sesuai paparan Kroeber dan Kluckhohn terdapat pada kebiasaan iklim yang tersurat muncul dalam cerita, yaitu beriklim panas. Dari cerita itu digambarkan bahwa tokoh telah terdampar di sebuah pulau selama lima hari. Walaupun berada di Indonesia, pada malam hari tetaplah dingin. Oleh karena itu, tokoh cerita digambarkan harus menyalakan api sebelum gelap. Pemunculan fakta musim di Indonesia menunjukkan perbandingan musim yang secara tidak sadar dilakukan oleh penulis yang notabene tidak berasal dari Indonesia. Kenyataan itu dapat dilihat pada kutipan berikut.

$\mathrm{Aku}$ harus menyalakan api secepat mungkin karena kalau matahari sudah tenggelam aku tidak akan mempunyai api untuk nanti malam. Meski aku berada di Indonesia, saat ini pada malam hari suhu udara menyatu dan tanpa api aku kedinginan.

\section{Keterkaitan antara Penguasaan Budaya Indonesia dan Kelengkapan Unsur-Unsur Cerita}

Keutuhan cerita didukung oleh keterkaitan antarunsur. Tidak hanya unsur yang membentuk dari dalam, tetapi juga unsur yang membentuk dari luar. Budaya dapat membentuk unsur-unsur cerita, baik dari dalam maupun luar. Oleh karena itu, dengan penguasaan budaya Indonesia yang mumpuni, cerita pendek yang dihasilkan akan lengkap unsur-unsurnya. Akan tetapi, ada beberapa cerita yang kurang 
utuh karena pijakan budaya yang ditampilkan kurang kuat. Hal itu dikarenakan oleh beberapa hal, misalnya kurang referensi terkait budaya yang akan ditonjolkan. Pada cerita berjudul "Blangkon" dipaparkan tentang tokoh yang berubah menjadi Pangeran Sudirman ke-2 setelah mengenakan blangkon yang ditemukan di lantai. Pangeran Sudirman itu digambarkan memimpin pada tahun 1403. Padahal, menurut sejarah Pangeran Sudirman merupakan pahlawan Indonesia yang melawan penjajah Belanda dan hidup pada masa 1916 - 1950. Jadi, tokoh yang dimunculkan pada cerita ini adalah tokoh fiktif yang bukan berlandaskan pada sejarah budaya Indonesia. Seharusnya cerita berangkat dari fakta sejarah. Tokoh fiktif itu terlihat pada kutipan berikut.

“Ada apa Tuanku?" Dua dua pria melihat saya dengan tampak takut dan nafas mereka tersengal-sengal. Tuan? Saya siapa?

"Kalian siapa?" saya bertanya

"Tuanku, kami hamba setia Tuan." Saya melihat mereka dengan wajah bingung.

"Kami hamba Pangeran Sudirman kedua", pria kedua berkata Pangeran Sudirman?

"Hari ini tanggal berapa?" Saya harus tau sekarang abad ke berapa?"

“Tanggal 27 Mei 1403, Tuan".

Karena latar belakang budaya yang kurang kuat, penulis cerita akhirnya menonjolkan kekuatan cerita dari segi yang lain. Pada cerita "Burung Toti" tidak dideskripsikan dengan jelas jenis burung yang merupakan tokoh utama. Seharusnya di akhir cerita dipaparkan jenis burung dengan kata kunci burung yang bisa dikonsumsi oleh manusia. Karena tidak mampu mendeskripsikan tokoh dan latar dengan detail, cerita lebih menonjolkan konflik tokoh, yaitu seorang burung yang mengalami perasaan dilema. Dilema karena senang bisa keluar dari toko burung yang telah memperangkapnya selama ini dan sedih karena akan dimakan oleh si bos yang membeli dirinya. Latar tempat, yaitu toko burung tidak dideskripsikan dengan detail. Toko burung hanya disebutkan saja tanpa mengekploitasi keberadaan toko burung dengan kepekaan indera pendengaran, penglihatan, penciuman, dan perasa. Padahal, tulisan imajinatif seharusnya menggali kemampuan visual dan emosi lebih mendalam. Kedangkalan latar itu terdapat pada kutipan berikut.

Saat pria terus berjalan saya menyadari bahwa ada banyak hal yang tidak pernah saya lihat sepanjang hidupku. Sebab saya terjebak dalam satu area di toko burung itu.

Di kedua pihak saya, ada begitu banyak hal yang belum saya pernah lihat. Ada begitu banyak warna yang saya tidak pernah mengalami dan baunya, aroma berubah setiap kali kita melewati toko yang berbeda di pasar ini.

Unsur cerita pada "Terlewat Perjalanan dari Bandung" kurang lengkap dengan kurang detailnya pengungkapan latar tempat. Latar tempat pada cerita ini berperan penting dalam keberlangsungan isi cerita. Jika tidak dipaparkan dengan jelas, akan menimbulkan kebingungan bagi pembaca. Pada awalnya tokoh cerita dikisahkan telah terlewat perjalanan ke Bandung. Ternyata ia telah naik kereta dan sampai di Tasikmalaya sehingga tiga jam lagi akan sampai di Yogyakarta. Tanpa disebutkan nama stasiun kereta api dan dari mana kereta api itu berangkat, pembaca akan bingung memprediksi dari mana kira-kira kereta itu berasal. Waktu tempuh antara Tasikmalaya dan Yogyakarta lebih dari tiga jam, yaitu sekitar 7 jam. Kelengkapan dan keakuratan informasi diperlukan untuk terhindar dari kerancuan isi cerita. Kenyataan itu terlihat pada kutipan berikut ini.

Setelah membereskan bajuku, saya cepatcepat menyetir mobilku ke stasiun kereta api dan naik kereta api ini.

"Bapak-bapak dan ibu-ibu terhormat, kita akan tiba di Yogyakarta dalam waktu tiga jam"

Apa? Yogyakarta? Aku seharusnya pergi ke Bandung! 
Representasi budaya yang dipaparkan pada cerita "Menjadi Seekor Tikus" sudah sesuai dengan kebiasaan di pasar Indonesia, tetapi informasi yang disampaikan kurang tepat. Dengan demikian, penguasaan budaya Indonesia penting untuk mengutuhkan cerita yang berlatar belakang Indonesia. Semangkuk harga bakso di pasar biasanya sekitar Rp 10,000,00-20.000,00. Di dalam cerita ini semangkuk bakso dijual seharga Rp 50.000,00. Konsep latar budaya penulis yang berbeda dengan budaya Indonesia menyebabkan ketidaktepatan ini. Kenyataan ini dapat kita lihat pada kutipan berikut ini.

"Bakso! Bakso! Hanya lima puluh ribu rupiah"

"Pepaya! Pepaya Segar!"

Kelengkapan unsur yang perlu dibangun dalam cerita "Lima Hari" adalah latar tempat. Jika unsur ini dilengkapi dengan detail, cerita ini akan lebih utuh dan menarik. Latar tempat di mana si tokoh terdampar selama lima hari di sebuah pulau terpencil yang tidak berpenghuni sebaiknya lebih detail dipaparkan dalam cerita walaupun tidak disebutkan namanya. Semakin detail unsur cerita dikisahkan, semakin lengkap unsur cerita yang terbangun sehingga lebih utuh.

\section{PENUTUP}

Hasil penelitian menunjukkan bahwa dari keenam tulisan imajinatif pemelajar BIPA kelas VCE 12 di Sacred Heart Girls College menggambarkan beberapa kategori budaya, khususnya budaya Indonesia sesuai yang disampaikan oleh Kroeber dan Kluckhohn. Hasil penelitian menggambarkan kategori budaya Indonesia yang tercermin dalam keenam cerita, yaitu perilaku normatif ("Berubah Menjadi Tikus" dan "Sesuatu di Balik Bantal"), kebiasaan ("Burung Toti" dan "Lima Hari”), sejarah pada warisan sosial dan tradisi (cerita "Blangkon"), psikologi, pengaturan (cerita "Sesuatu di Balik Bantal"), psikologi, dan pembelajaran (cerita "Terlewat Perjalanan dari Bantal").

Penguasaan budaya Indonesia dan kelengkapan unsur-unsur cerita saling terkait.
Jika pijakan unsur budaya tidak kuat, cerita yang disampaikan tidak lengkap dan utuh. Ketidaklengkapan cerita itu terlihat pada penyampaian latar tempat dan tokoh, serta budaya yang tidak detail sehingga menunjukkan kepekaan budaya penulis yang masih kurang. Penulis mengatasi penguasaan budaya yang masih terbatas itu adalah dengan menonjolkan segi cerita yang lain, misalnya konflik antartokoh.

\section{DAFTAR PUSTAKA}

Baldwin, John R, dkk. (2006), “A Moving Target: The Illusive Definition of Culture" dalam Redefining Culture: Perspective Across the Disciplines. New Jersey: Lawrence Erlbaum Associates, Inc.

Burroway, Janet. (2015). Imaginative Writing: The Element of Craft. Forth Edition. Pearson: United States.

Jumadi. (2017), Wacana, Kekuasaan, Pendidikan Bahasa. Pustaka Pelajar: Yogyakarta

Levine, Robert A. (2009), Culture, Behaviour, and Personality: An Introduction to the Comparative Study of Psychosocial Adaptation. Unites States of America: Library of Congress.

McNamee, Maurice B, dkk. (1971), Literary Types and Themes. New York: Holt, Rinehart and Winston, Inc.

Nurgiyantoro, Burhan. (1998), Teori Pengkajian Fiksi. Yogyakarta: Gadjah Mada University Press. . (2013), Sastra Anak: Pengantar Dunia Anak. Yogyakarta: Gadjah Mada University Press.

Parsons, Falcott. (1972) "Culture and Sosial System Revisited". http://www.jstor.org/ stable/42858956. (diakses tanggal 13 Maret 2018).

Poyatos, Fernando (Ed.). (1988), Literary Antropology: A New Interdisciplinary Approach to People, Signs, and Literature. Amsterdam and Philadelphia: John Benjamins Publishing Company. 
Ratna, Nyoman Kutha. (2006), Teori, Metode, dan Teknik Penelitian Sastra. Yogyakarta: Pustaka Pelajar.

Semi, Atar. (1988), Anatomi Sastra. Padang: Angkasa Raya.

Suyitno, Imam. (2017) "Pemahaman Budaya dalam Pembelajaran Bahasa Indonesia bagi Penutur asing (BIPA)". https://www. researchgate.net/publication/315456935. (diakses tanggal 12 April 2018).
Thahar, Harris Effendi. (1999) Kiat menulis Cerita Pendek. Angkasa: Bandung.

Weiss, Gerald. (1973) "A Scientific Concept of Culture". Http://www.jstor.org/ stable/67403. (diakses tanggal 13 Maret 2018).

How To Cite : Riana, D. (2018). PENGUASAAN BUDAYA INDONESIA DALAM TULISAN IMAJINATIF (STUDI KASUS SISWA DI SACRED HEART GIRLS COLLEGE, AUSTRALIA) Mastering Indonesian Culture in Imaginative Writing (Student Case Study in the Sacred Heart Girls College, Australia). SAWERIGADING, 24(2), 177-184. doi:http:// dx.doi.org/10.26499/sawer.v24i2.508 